\title{
System of gait analysis based on ground reaction force assessment
}

\author{
František Vaverka ${ }^{1, *}$, Milan Elfmark², Zdeněk Svoboda ${ }^{2}$, and Miroslav Janura²

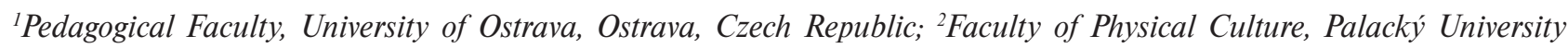 \\ Olomouc, Olomouc, Czech Republic
}

Copyright: (C) 2015 F. Vaverka et al. This is an open access article licensed under the Creative Commons Attribution License (http://creativecommons.org/licenses/by/4.0/).

\begin{abstract}
Background: Biomechanical analysis of gait employs various methods used in kinematic and kinetic analysis, EMG, and others. One of the most frequently used methods is kinetic analysis based on the assessment of the ground reaction forces (GRF) recorded on two force plates. Objective: The aim of the study was to present a method of gait analysis based on the assessment of the GRF recorded during the stance phase of two steps. Methods: The GRF recorded with a force plate on one leg during stance phase has three components acting in directions: Fx - mediolateral, Fy - anteroposterior, and Fz - vertical. A custom-written MATLAB script was used for gait analysis in this study. This software displays instantaneous force data for both legs as $\mathrm{Fx}(\mathrm{t}), \mathrm{Fy}(\mathrm{t})$ and $\mathrm{Fz}(\mathrm{t})$ curves, automatically determines the extremes of functions and sets the visual markers defining the individual points of interest. Positions of these markers can be easily adjusted by the rater, which may be necessary if the GRF has an atypical pattern. The analysis is fully automated and analyzing one trial takes only 1-2 minutes. Results: The method allows quantification of temporal variables of the extremes of the $\mathrm{Fx}(\mathrm{t}), \mathrm{Fy}(\mathrm{t}), \mathrm{Fz}(\mathrm{t})$ functions, durations of the braking and propulsive phase, duration of the double support phase, the magnitudes of reaction forces in extremes of measured functions, impulses of force, and indices of symmetry. The analysis results in a standardized set of 78 variables (temporal, force, indices of symmetry) which can serve as a basis for further research and diagnostics. Conclusions: The resulting set of variable offers a wide choice for selecting a specific group of variables with consideration to a particular research topic. The advantage of this method is the standardization of the GRF analysis, low time requirements allowing rapid analysis of a large number of trials in a short time, and comparability of the variables obtained during different research measurements.
\end{abstract}

Keywords: gait, kinetic analysis, force plate, time variables, force variables, symmetry indices

\section{Introduction}

Gait analysis uses a number of research methods: kinematics (Branco, Santos-Rocha, Aguiar, Vieira, \& Veloso, 2013), kinetics (Kim \& Lee, 2013), EMG (Wentink, Prinsen, Rietman, \& Veltink, 2013), and various other methods employing devices such as accelerometers, gyroscopes, and magnetoresistive sensors (Paquet, Auvinet, Chaleil, \& Barrey, 2003; Tao, Liu, Zheng, \& Feng, 2012). Combinations of different methods are frequently employed (Gross et al., 2014). When kinematic and kinetic analyses are combined, inverse dynamics can then be used to obtain variables such as resultant moments of forces or powers

\footnotetext{
* Address for correspondence: František Vaverka, Department of Human Movement Studies, Pedagogical Faculty, University of Ostrava, Varenská 40, 70100 Ostrava, Czech Republic. Email: frantisek.vaverka@gmail.com
}

in individual joints of lower limbs (Hamill \& Selbie, 2004).

Kinematic analysis and EMG measurements require time-consuming process of attaching skin markers and electrodes onto the body of the examined person. On the other hand, assessment of force-time curves of the ground reaction forces (GRF) acquired with a force plate has a considerable advantage of a possibility of immediate visual inspection of a measured trial. GRF measurement is a relatively simple method which allows obtaining the magnitudes of reaction forces acting on the human body. Speed and relative simplicity of obtaining the GRF data led to wide-spread use of this method. Reliability of GRF data is considered to be higher than that of kinematic data (Ferber, McClay Davis, Williams, \& Laughton, 2002; Fortin, Nadeau, \& Labelle, 2008). Contrary to the kinematic analysis where the data are usually analyzed with standard 
commercially available software (e.g., Vicon, Qualisys, Elite), the software provided by the force plate manufacturers may not be best suited for a routine assessment of a large amount of variables. Consequently, the analysis of a GRF record often requires custom-written software adapted to specific needs of various research experiments.

Temporal and kinetic variables obtained from the analysis of the GRF are varied and their selection depends on the researcher's needs. Most attention is on the vertical component of the GRF which is the force with the largest magnitude that the ground reacts on the body. The most frequently assessed variables are force magnitudes at individual peaks of the force-time curve of the vertical component and force peaks of the anteroposterior (AP) component in the braking and propulsive phases (Fortin et al., 2008; Vanicek, Strike, McNaughton, \& Polman, 2009). Analysis of temporal and force variables in the mediolateral (ML) direction is used less frequently (Fortin et al., 2008) due to their relatively high variability (Svoboda, Janura, Cabell, \& Elfmark, 2012). A large number of proposed temporal and force variables was listed in the study by Racic, Pavic, and Brownjohn (2009).

In addition to force variables obtained from the extremes of the curve, other variables derived from the basic ones (time, force) are used, such as loading and unloading rates in the initial and final phases of the step (Cook, Farrell, Carey, Gibbs, \& Wiger, 1997), time from the initial contact to the first maximum peak and time from the second maximum peak to the toe-off of the vertical component curve (Vanicek et al., 2009) and others. One of the parts of the GRF analysis is the computation of impulses of force in individual subphases of the gait stance phase. Specific information can be obtained from symmetry indices (SI), computed from basic temporal and force variables (Cigali, Ulucam, Yilmaz, \& Cakiroglu, 2004; Kodesh, Kafri, Dar, \& Dickstein, 2012; Michalski, Wit, \& Gajewski, 2011; Shorter, Polk, Rosengren, \& Hsiao-Wecksler, 2008).

Due to a large number of gait analyses conducted in the biomechanical laboratory at the Faculty of Physical Culture, Palacký University Olomouc, Czech Republic, it was deemed necessary to create a standardized system of the GRF analysis; a system that could provide a vast choice of evaluated variables. Such a set of obtained variables allows the researcher to choose the specific ones required for a particular research problem. The aim of the study was to present this system used for analysis of the GRF recorded with two force plates during gait and the variables the system offers to the researcher.

\section{Methods}

\section{Theoretical basis and methodology design}

The resultant GRF recorded with a force plate has three components acting in directions: Fx - mediolateral (ML), Fy - anteroposterior (AP), and Fz - vertical, see Figure 1A. The ML component affects balance in the mediolateral plane, the AP component affects deceleration and acceleration of movement, and the vertical component acts perpendicular to the ground against the gravitational force. The proposed method is based on the fact that the general pattern of these three GRF components is similar across individuals (Figure 1A). The individual persons differ in magnitudes of extremes and temporal variables of recorded force-time curves. High level of reliability of kinetic variables obtained from the GRF record, particularly in the AP and vertical directions (Kadaba et al., 1989; Steinwender et al., 2000; White, Agouris, Selbie, \& Kirkpatrick, 1999) manifests in high intra-class individual stability of force-time curve patterns.

The presented method determines predefined temporal and force variables and indices of symmetry based on the three components of the GRF recorded during stance phase of gait. The system used in this method quantifies temporal variables of extremes of the $\mathrm{Fx}(\mathrm{t}), \mathrm{Fy}(\mathrm{t})$ a Fz(t) functions, durations of the braking and propulsion phases and the double support, and the total duration of the stance phase of two steps. As for kinetic variables, magnitudes of reaction forces in extremes of measured functions and impulses of force in individual phases of a step are evaluated. The system also computes symmetry indices (SI) for variables measured on one limb and also between variables measured on both limbs. Graphical display of temporal and force variables of one step, duration of double support and the total duration of the stance phase of two steps is in Figure 1B and 2. A brief description of measured variables is given in captions of Figure 1 and 2; SIs are described in Table 1. Additionally, the system computes and displays a trajectory of the center of pressure (COP) in the stance phase of two steps (Figure 3C).

A symmetry index for a single step is computed as the ratio between variables in the braking and propulsion phases, resulting in the total of three SIs for one limb. Symmetry of two steps is computed as follows: a variable measured on the right leg is divided by the same variable measured on the left leg. Symmetry indices are computed for all three components of the GRF and all measured variables (26 SIs in total). The total number of force, temporal and symmetry variables provided by the system is 78 . 
A

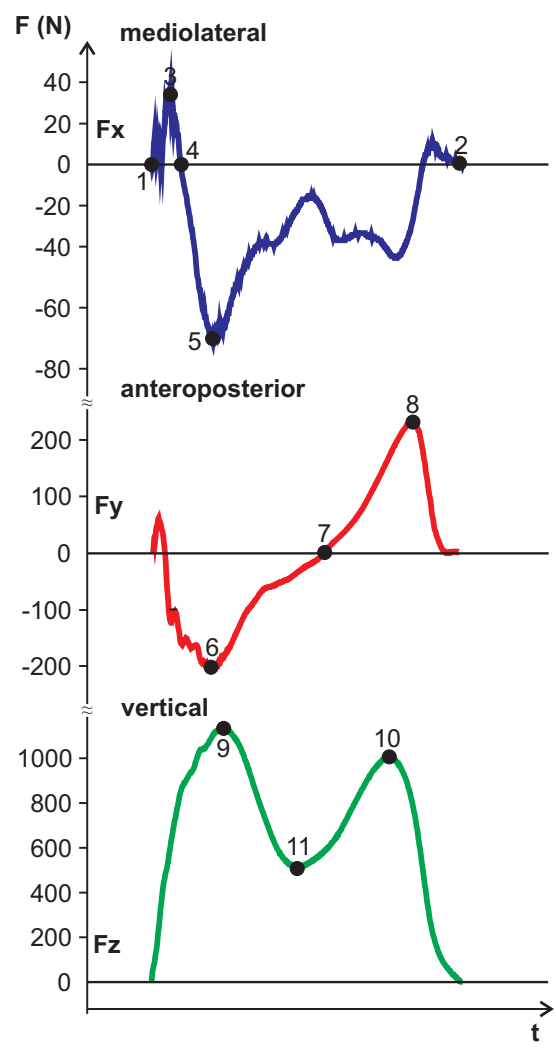

B

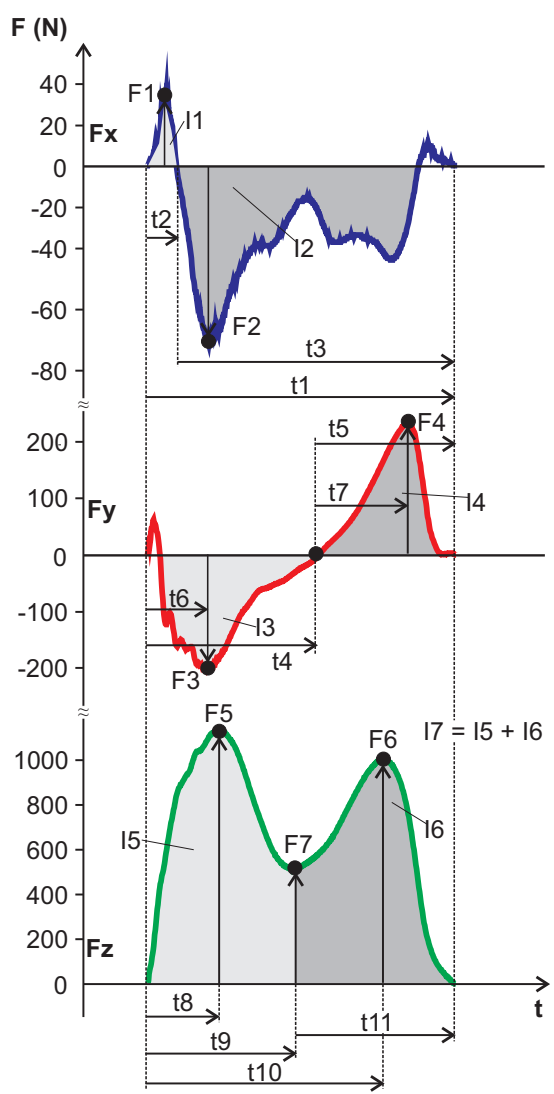

Figure 1. The ground reaction force during the stance phase of one step (A). Graphical illustration of temporal and force variables of the three GRF components (B). $\mathrm{t} 1$ = duration of stance phase; Fx - mediolateral component: $\mathrm{F} 1=$ lateral peak, $\mathrm{F} 2=$ medial peak, $\mathrm{t} 2=$ duration of force acting in the lateral direction, $\mathrm{t} 3$ = duration of force acting in the medial direction, $\mathrm{I} 1$ = lateral impulse, $\mathrm{I} 2$ = medial impulse; $F y$ - anteroposterior component: $\mathrm{F} 3$ = braking peak, $\mathrm{F} 4=$ propulsive peak, $\mathrm{t} 4=$ duration of the braking phase, $\mathrm{t} 5=$ duration of the propulsive phase, $\mathrm{t} 6=$ time to braking peak, $\mathrm{t} 7$ = time to propulsive peak, $\mathrm{I} 3$ = braking impulse, $\mathrm{I} 4$ = propulsive impulse; $\mathrm{Fz}$ - vertical component: $\mathrm{F} 5$ = loading response peak, $\mathrm{F} 6=$ terminal stance peak, $\mathrm{F} 7=$ midstance valley, $\mathrm{t} 8=$ time to loading response peak, $\mathrm{t} 9=$ time to midstance valley, $\mathrm{t} 10=$ time to terminal stance peak, $\mathrm{t} 11=$ time from midstance valley to toe off, $\mathrm{I} 5=$ impulse of loading response and midstance, I 6 = impulse of terminal stance and preswing, I7 = total impulse of the vertical GRF.

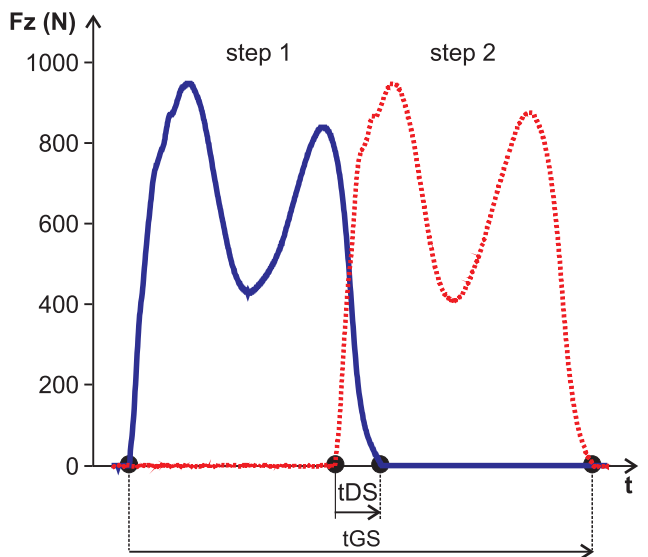

Figure 2. Vertical components of the GRF of two steps and measured variables. $\mathrm{tDS}=$ double support duration, $\mathrm{tGS}=$ duration of gait stride: from the initial contact of one leg to the toe off of the other leg (Inman, Ralston, \& Todd, 1981).

\section{GRF analysis procedure}

Analysis of the GRF of two steps recorded with two force plates comprises following steps:

1. GRF data acquired with two force plates during the stance phase of gait are exported to a text file and then imported into the custom-written software created by the authors of the paper, implemented in MATLAB (MathWorks, Nattick, MA, USA). The data are then filtered with the 2nd order band-pass Butterworth filter $(0.1 \mathrm{~Hz}$ low and $20 \mathrm{~Hz}$ high cutoff frequency) (Winter, 2009). Initial contact (heel strike) was determined as the instant where the vertical GRF exceeded 5\% of body weight. Similarly, toe-off was determined as the instant where the vertical GRF dropped below 5\% of body weight. Accuracy of temporal variables depends on the sampling rate of the measurement. The commonly 
used sampling rates for gait analysis range between 200 and $1000 \mathrm{~Hz}$.

2. The software displays the three GRF components recorded for both limbs as Fx(t), Fy(t), and Fz(t) curves. Eleven predefined points characterizing the extremes of functions and selected time intervals (Figure 1A) are then automatically determined by the software and marked with a circlet (Figure 3A). Additionally, a COP trajectory computed from the data recorded with force plates is displayed for both right and left limb (Figure 3C). The first analysis report contains a table with temporal and force values for the three observed functions and the COP coordinates on a force plate in eleven predefined points of the GRF curve (Figure 3B). Accuracy of the evaluated force variables is limited by the technical parameters of the force plate.

3. The third step of the analysis is a visual inspection of the automatically-set markers for their correctness, performed by the rater. The rater has to decide whether the curves have typical shapes and whether the markers' positions match the predefined model (Figure 1A). If the curve shapes are atypical (e.g., invalid trial, effect of a specific oral instruction, other factors), the rater decides whether the trial is invalid and not to be used or if positions of the markers are to be manually adjusted.

4. The next step of the analysis is displaying a final report of the computed variables (Figure 4).

5. For the final step of the analysis, the computed variables are exported to a text file which can then be further processed.

\section{Discussion}

Extremes of functions of the individual GRF components and predetermined points on the time axis are

Table 1

Symmetry indices

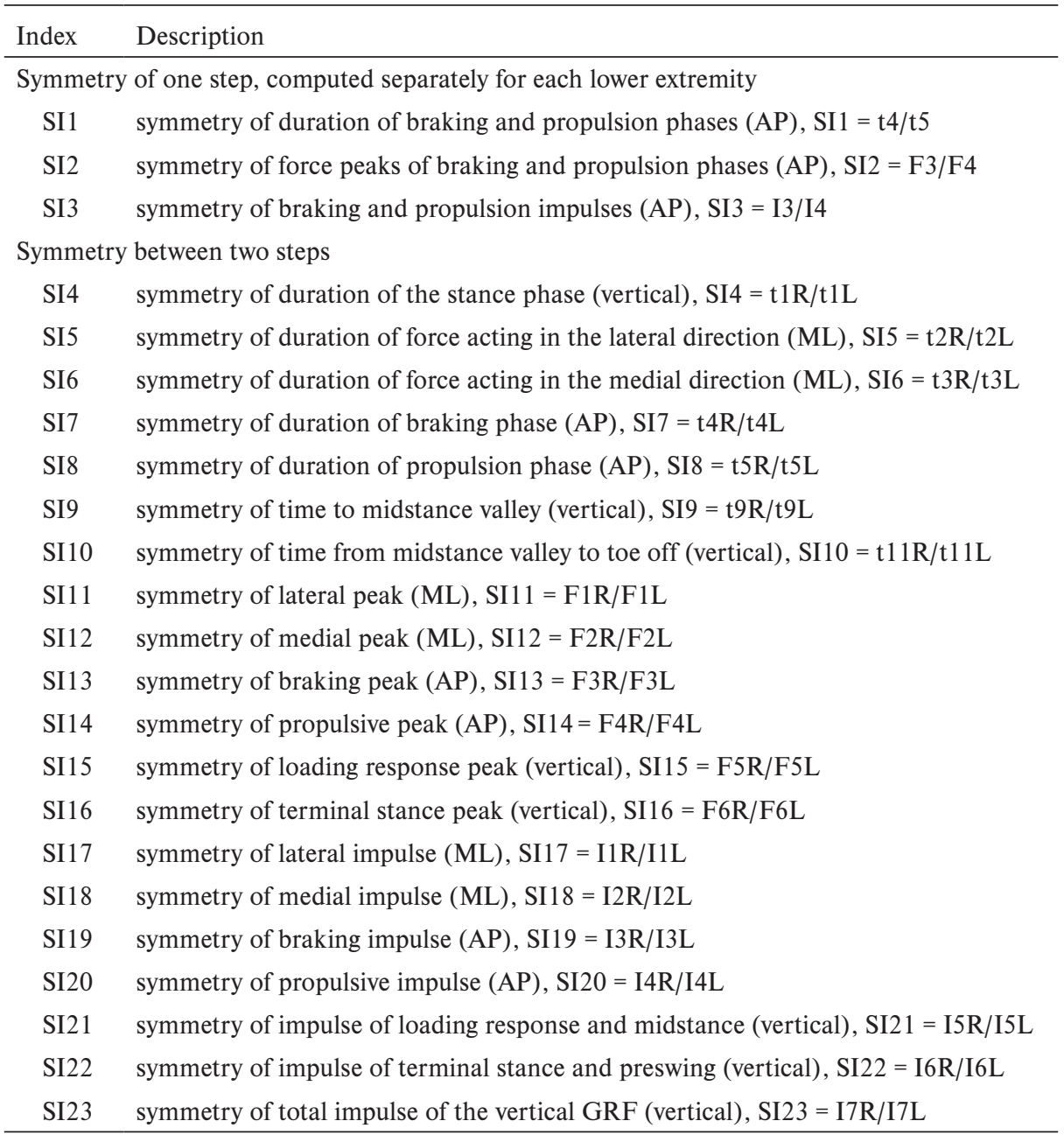

Note. $\quad \mathrm{SI}=$ symmetry index, $\mathrm{ML}=$ mediolateral component of the $\mathrm{GRF}, \mathrm{AP}=$ anteroposterior component of the GRF, vertical = vertical component of the GRF, $t=$ temporal variables, $F=$ force variables, $\mathrm{I}=$ impulse variables, $\mathrm{R}=$ right lower extremity, $\mathrm{L}=$ left lower extremity. 
A
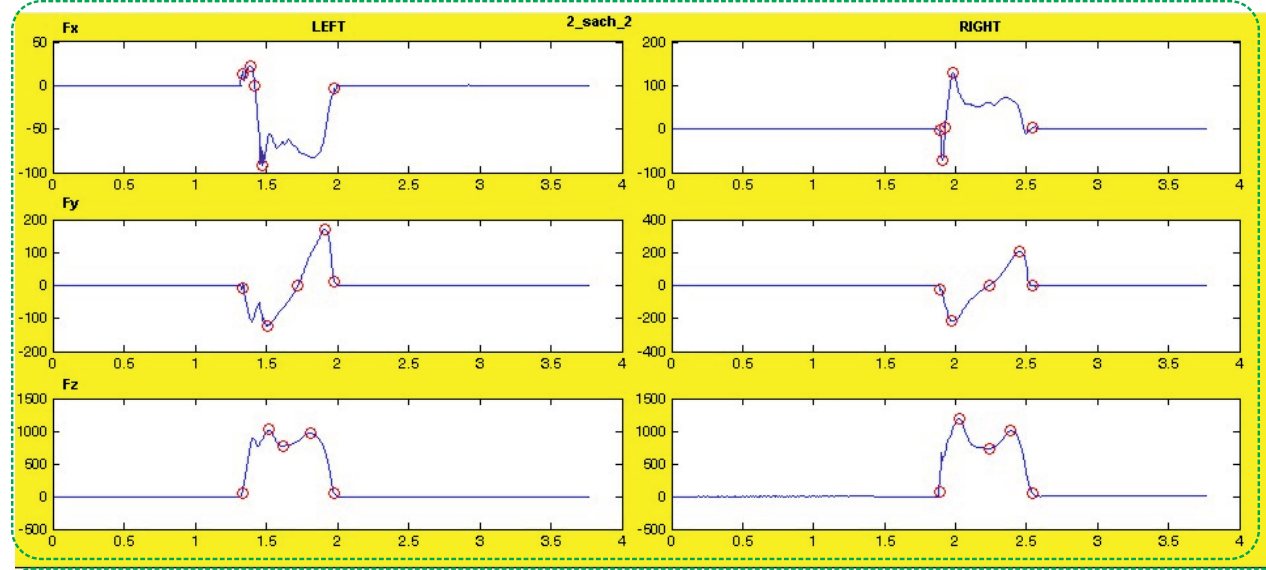

C

\begin{tabular}{|c|c|c|c|c|c|c|c|c|c|c|c|c|c|c|c|c|}
\hline & Time & $\overline{F x}$ & Fy & $\mathrm{Fz}$ & $A x$ & $\mathrm{Ay}$ & Tra & Time & $F x$ & Fy & $\overline{F z}$ & $A x$ & Ay & Tra & test & \\
\hline 1 & 1.33 & 13.09 & -9.85 & 53.10 & 14.96 & 14.49 & 0.56 & 1.89 & -3.42 & -21.17 & 68.65 & -15.42 & 9.16 & 3.09 & 1_sach_1 & $\hat{A}$ \\
\hline 2 & 1.98 & -2.92 & 12.02 & 51.13 & 12.19 & -10.80 & 29.20 & 2.55 & 2.89 & -3.32 & 52.16 & -9.44 & -16.97 & 35.38 & $\begin{array}{l}1-\text { sach }_{2}^{2} \\
1-\operatorname{sich}^{2}\end{array}$ & 酌 \\
\hline 3 & 1.39 & 22.35 & -106.12 & 786.01 & 14.46 & 12.34 & 4.22 & 1.91 & -72.93 & -47.68 & 555.26 & -14.00 & 7.73 & 5.98 & 1 sach-1 1 r & \\
\hline 4 & 1.42 & -0.69 & -88.13 & 874.37 & 14.15 & 11.61 & 5.05 & 1.93 & 4.74 & -125.34 & 672.26 & -12.34 & 5.15 & 9.06 & $\begin{array}{l}1 \text { sach- } 2-r \\
1-3 \operatorname{sach} 3-3 r\end{array}$ & \\
\hline 5 & 1.47 & -92.27 & -102.21 & 885.39 & 12.08 & 7.00 & 10.29 & 1.98 & 130.53 & -215.67 & 1037.46 & -10.27 & 1.03 & 13.72 & $\begin{array}{l}\text { 2-sach-1 } \\
2 \text { _sach_-2 }\end{array}$ & \\
\hline 6 & 1.51 & -66.42 & -121.10 & 998.37 & 11.61 & 3.35 & 13.97 & 1.97 & 114.82 & -217.19 & 952.04 & -10.36 & 1.30 & 13.41 & $\begin{array}{l}\text { 2_sach_3 } \\
1 \text { _sach_1_r }\end{array}$ & \\
\hline 7 & 1.72 & -73.58 & 0.04 & 841.42 & 10.23 & -5.38 & 22.87 & 2.24 & 61.83 & 0.16 & 732.05 & -6.87 & -8.58 & 24.63 & 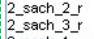 & $v$ \\
\hline 8 & 1.91 & -55.82 & 169.97 & 701.42 & 10.64 & -7.62 & 25.23 & 2.45 & 41.34 & 208.55 & 831.67 & -9.00 & -11.66 & 28.45 & & \\
\hline 9 & 1.52 & -56.35 & -120.11 & 1020.54 & 11.49 & 2.14 & 15.18 & 2.03 & 80.50 & -183.68 & 1185.45 & -10.57 & -0.57 & 15.37 & left & इबक \\
\hline 10 & 1.81 & -82.21 & 92.69 & 968.97 & 10.50 & -6.12 & 23.69 & 2.39 & 69.03 & 150.70 & 1002.95 & -8.25 & -10.53 & 27.08 & Trial & \\
\hline 11 & 1.62 & -64.75 & -72.52 & 764.05 & 10.22 & -4.27 & 21.74 & 2.24 & 61.85 & -0.38 & 731.85 & -6.88 & -8.58 & 24.63 & & \\
\hline
\end{tabular}

B

Figure 3. Gait analysis, first analysis output. Fx, Fy and Fz force-time curves of two steps (A); values of time, force and COP position at 11 defined points $(B$, see Figure 1A); trajectory of the COP on a force plate (C). LEFT, L = left lower extremity; RIGHT, R = right lower extremity.

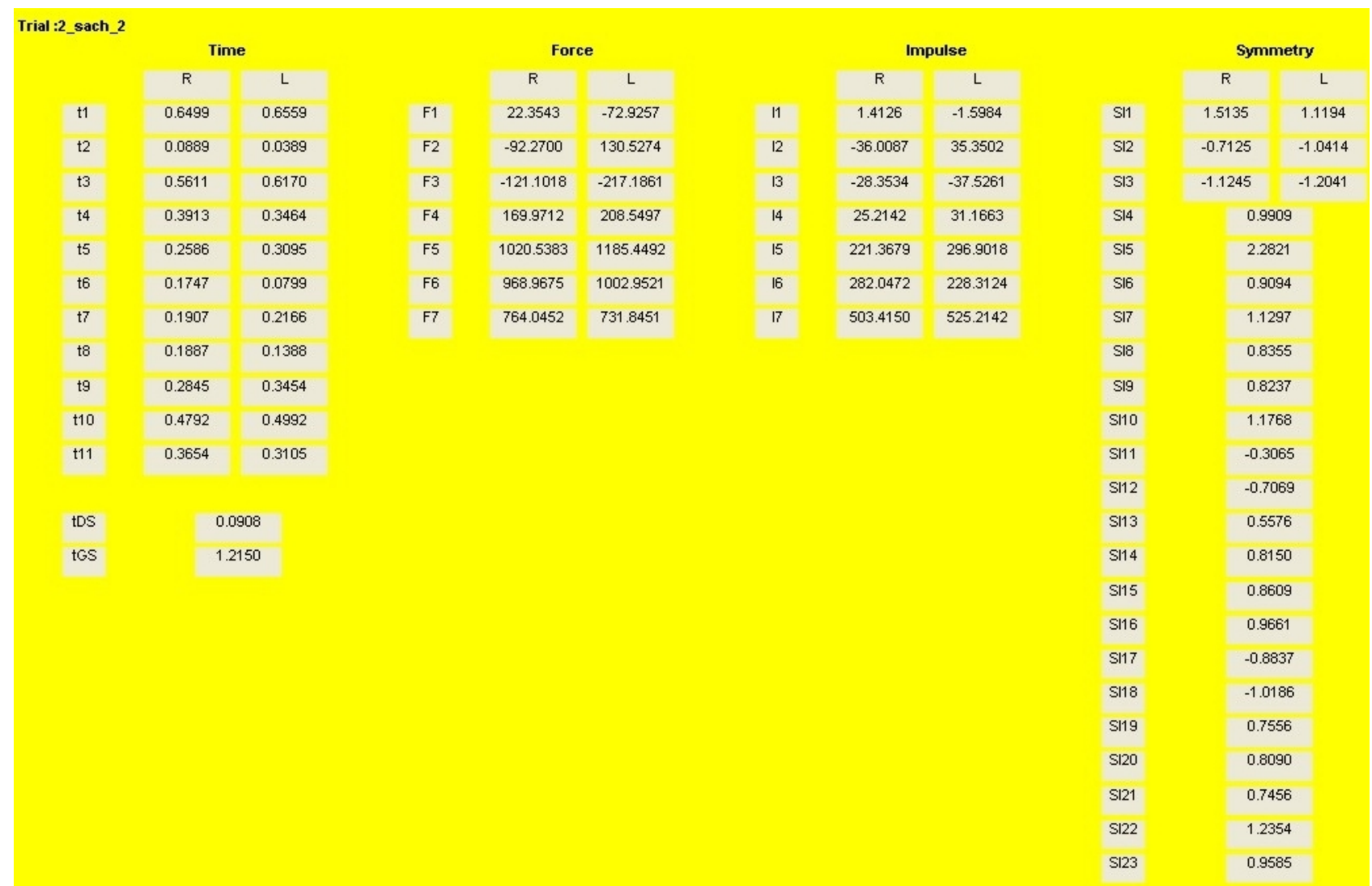

Figure 4. Gait analysis, the final outcome of computed variables. $\mathrm{R}=$ right lower extremity, $\mathrm{L}=$ left lower extremity. 
automatically set by the software. Accuracy may be decreased if positions of the markers were manually adjusted by the rater in cases where the software was unable to properly determine their positions automatically based on to the model described in Figure 1A. Long-time use of the software has shown that the vast majority of recorded trials' data conforms to the typical GRF pattern (Fx: a single peak in medial and lateral parts, Fy: a single peak in the braking and propulsion phases, Fz: two maximum and one minimum peaks; see Figure 1A) and the number of trials that does not is generally very low. The exception may be the ML force-time curve $(\mathrm{Fx})$, where the markers are occasionally placed improperly by the software; this curve has a higher rate of occurrence of atypical shapes.

A symmetry index computed as the ratio between two values serves only as a starting point for analysis of symmetry of movement and force-time variables can be used to compute symmetry indices in other ways (VanZant, McPoil, \& Cornwall, 2001). In theory, in an able-bodied persons gait can be considered to be symmetrical. In practice, there are numerous discrepancies in gait symmetry and small deviations (in the range of several per cents) from the ideal symmetry are deemed physiologically acceptable. Gait symmetry is affected by many factors such as laterality (Sadeghi, Allard, Prince, \& Labelle, 2000; Wang \& Watanabe, 2012), preferred take-off leg in jumping (Miyaguchi \& Demura, 2010), anatomical and functional disproportions of lower limbs (White, Gilchrist, \& Wilk, 2004), health issues affecting one limb (Becker, Rosenbaum, Kriese, Gerngross, \& Claes, 1995), and others. Symmetry indices significantly different from the theoretical symmetry of 1.0 can serve as a signal drawing attention to the cause of such a difference. SIs for the ML direction in the presented system are computed only for the peak force and medial and lateral impulses. The reason for this is a large within and between session variability of temporal variables which results in their low repeatability (Kadaba et al., 1989).

Gait assessment using two force plates can be considered to be the standard way used for obtaining kinetic variables during the gait stance phase. The GRF-based analysis has a number of advantages. Measured data displayed as force-time curves can be immediately inspected. Accuracy of the manual marker adjustment can be increased using the built-in zoom feature, which allows enlarging visible area around a particular marker.

Obtained force and temporal variables can serve as a basis for calculation of other derived variables, such as force variables normalized to body weight, temporary variables normalized to duration of the stance phase, various coefficients calculated from force-time variables (e.g. Vanicek et al., 2009), and others. In repeated experiments or comparative research studies it is advantageous to use the data obtained with exactly same methodology which has constant accuracy.

The method presented in this study has been used for a long time for gait analyses in the biomechanical laboratory at the Faculty of Physical Culture, Palacký University, Olomouc. Results of the analyses have been used in Master theses, doctoral dissertations and scientific papers (Martinásková, Gallo, Kamínek, \& Janura, 2014; Svoboda et al., 2012).

\section{Conclusions}

Kinetic analysis of the GRF of two steps measured with two force plates ranks among the frequently used methods for gait analysis. The method presented in this paper is based around custom software made in MATLAB. Visual inspection of shapes of the GRF curves and the possibility of manual adjustment of the markers allows for more precise selection of individual trials into the data set intended for further data analysis. This method of the GRF analysis provides a total of 78 variables (temporal, force, indices of symmetry). These variables can serve as a basis for calculation of derived or modified variables, such as force variables normalized to body weight, temporal variables normalized to the stance phase duration, and others. The resulting set of variables offers a wide range of variables to choose from depending on the researcher's needs. Automation of the analysis facilitates a rapid assessment of a great number of trials in a short time. Another advantage of this method is a standardization of the GRF assessment and comparability of obtained variables across different research tasks.

\section{Acknowledgments}

This study was supported by the Czech Science Foundation grant No. 15-13980S.

\section{References}

Becker, H. P., Rosenbaum, D., Kriese, T., Gerngross, H., \& Claes, L. (1995). Gait asymmetry following successful surgical treatment of ankle fractures in young adults. Clinical Orthopaedics and Related Research, 311, 262-269.

Branco, M., Santos-Rocha, R., Aguiar, L., Vieira, F., \& Veloso, A. (2013). Kinematic analysis of gait in the second and third trimesters of pregnancy. Journal of Pregnancy, 2013, 718095. doi:10.1155/2013/718095 
Cigali, B. S., Ulucam, E., Yilmaz, A., \& Cakiroglu, M. (2004). Comparison of asymmetries in ground reaction force patterns between normal human gait and football players. Biology of Sport, 21, 241-248.

Cook, T. M., Farrell, K. P., Carey, I. A., Gibbs, J. M., \& Wiger, G. E. (1997). Effects of restricted knee flexion and walking speed on the vertical ground reaction force during gait. Journal of Orthopaedic and Sports Physical Therapy, $25,236-244$.

Ferber, R., McClay Davis, I., Williams, D. S., \& Laughton, C. (2002). A comparison of within- and between-day reliability of discrete 3D lower extremity variables in runners. Journal of Orthopaedic Research, 20, 1139-1145. doi:10.1016/S0736-0266(02)00077-3

Fortin, C., Nadeau, S., \& Labelle, H. (2008). Inter-trial and test-retest reliability of kinematic and kinetic gait parameters among subjects with adolescent idiopathic scoliosis. European Spine Journal, 17, 204-216. doi:10.1007/ s00586-007-0469-9

Gross, R., Delporte, L., Arsenault, L., Revol, P., Lefevre, M., Clevenot, D., ... Luauté, J. (2014). Does the rectus femoris nerve block improve knee recurvatum in adult stroke patients? A kinematic and electromyographic study. Gait and Posture, 39, 761-766. doi:10.1016/j. gaitpost.2013.10.008

Hamill, J., \& Selbie, S. (2004). Three-dimensional kinetics. In G. E. Robertson, G. E. Caldwell, J. Hamill, G. Kamen, \& S. Whittlesey (Eds.), Research methods in biomechanics (pp. 145-162). Champaign, IL: Human Kinetics.

Inman, V. T., Ralston, H. J., \& Todd, F. (1981). Human walking. Baltimore, MD: Williams \& Wilkins.

Kadaba, M. P., Ramakrishnan, H. K., Wootten, M. E., Gainey, J., Gorton, G., \& Cochran, G. V. B. (1989). Repeatability of kinematic, kinetic, and electromyographic data in normal adult gait. Journal of Orthopaedic Research, 7, 849-860. doi:10.1002/jor.1100070611

Kim, M. K., \& Lee, Y. S. (2013). Kinematic analysis of the lower extremities of subjects with flat feet at different gait speeds. Journal of Physical Therapy Science, 25, 531-533. doi:10.1589/jpts. 25.531

Kodesh, E., Kafri, M., Dar, G., \& Dickstein, R. (2012). Walking speed, unilateral leg loading, and step symmetry in young adults. Gait and Posture, 35, 66-69. doi:10.1016/j. gaitpost.2011.08.008

Martinásková, E., Gallo, J., Kamínek, P., \& Janura, M. (2014). Ground reaction force in patients after total hip arthroplasty revision - a pilot study. In D. Milanović \& G. Sporiš (Eds.), 7th International Scientific Conference on Kinesiology "Fundamental and Applied Kinesiology - Steps Forward": Proceedings (pp. 174-176). Zagreb, Croatia: University of Zagreb.

Michalski, R., Wit, A., \& Gajewski, J. (2011). Use of artificial neural networks for assessing parameters of gait symmetry. Acta of Bioengineering and Biomechanics, 13, 65-70.

Miyaguchi, K., \& Demura, S. (2010). Specific factors that influence deciding the takeoff leg during jumping movements. Journal of Strength and Conditioning Research, 24, 2516-2522. doi:10.1519/JSC.0b013e3181e380b5

Paquet, J. M., Auvinet, B., Chaleil, D., \& Barrey, E. (2003). Analyse des troubles de la marche par une méthode accélérométrique dans la maladie de Parkinson [Analysis of gait disorders in Parkinson's disease assessed with an accelerometer]. Revue Neurologique, 159, 786-789.

Racic, V., Pavic, A., \& Brownjohn, J. M. W. (2009). Experimental identification and analytical modelling of human walking forces: Literature review. Journal of Sound and Vibration, 326, 1-49. doi:10.1016/j.jsv.2009.04.020

Sadeghi, H., Allard, P., Prince, F., \& Labelle, H. (2000). Symmetry and limb dominance in able-bodied gait: A review. Gait and Posture, 12, 34-45.

Shorter, K. A., Polk, J. D., Rosengren, K. S., \& HsiaoWecksler, E. T. (2008). A new approach to detecting asymmetries in gait. Clinical Biomechanics, 23, 459-467. doi:10.1016/j.clinbiomech.2007.11.009

Steinwender, G., Saraph, V., Scheiber, S., Zwick, E. B., Uitz, C., \& Hackl, K. (2000). Intrasubject repeatability of gait analysis data in normal and spastic children. Clinical Biomechanics, 15, 134-139.

Svoboda, Z., Janura, M., Cabell, L., \& Elfmark, M. (2012). Variability of kinetic variables during gait in unilateral transtibial amputees. Prosthetics and Orthotics International, 36, 225-230. doi:10.1177/0309364612439572

Tao, W., Liu, T., Zheng, R., \& Feng, H. (2012). Gait analysis using wearable sensors. Sensors, 12, 2255-2283. doi:10.3390/s120202255

Vanicek, N., Strike, S., McNaughton, L., \& Polman, R. (2009). Gait patterns in transtibial amputee fallers vs. non-fallers: Biomechanical differences during level walking. Gait and Posture, 29, 415-420. doi:10.1016/j. gaitpost.2008.10.062

VanZant, R. S., McPoil, T. G., \& Cornwall, M. W. (2001). Symmetry of plantar pressures and vertical forces in healthy subjects during walking. Journal of the American Podiatric Medical Association, 91, 337-342.

Wang, Y., \& Watanabe, K. (2012). Limb dominance related to the variability and symmetry of the vertical ground reaction force and center of pressure. Journal of Applied Biomechanics, 28, 473-478.

Wentink, E. C., Prinsen, E. C., Rietman, J. S., \& Veltink, P. H. (2013). Comparison of muscle activity patterns of transfemoral amputees and control subjects during walking. Journal of NeuroEngineering and Rehabilitation, 10, 87. doi:10.1186/1743-0003-10-87

White, R., Agouris, I., Selbie, R. D., \& Kirkpatrick, M. (1999). The variability of force platform data in normal and cerebral palsy gait. Clinical Biomechanics, 14, 185192. doi:10.1016/S0268-0033(99)80003-5

White, S. C., Gilchrist, L. A., \& Wilk, B. E. (2004). Asymmetric limb loading with true or simulated leg-length differences. Clinical Orthopaedics and Related Research, 421, 287-292.

Winter, D. (2009). Biomechanics and motor control of human movement (4th ed.). Hoboken, NJ: John Wiley \& Sons. 